\title{
O uso das geotecnologias na análise socioespacial
}

\author{
Glaucio José Marafon \\ Paulo Vinicius Rufino Fevrier \\ Renata da Silva Corrêa
}

Passado mais de um século desde a institucionalização da geografia, muito ainda se tem discutido sobre a definição do objeto de estudo de tal ramo do conhecimento. Entre as várias perspectivas que surgem na história do pensamento geográfico, encontra-se o espaço, como vital, singularizado, quantificado, abordado criticamente ou no viés mais fenomenológico. Assim, tem-se buscado entender a importância desse conceito para as análises e reflexões sobre os fenômenos que se processam nas interações do homem em sociedade intermediadas pela materialidade presente na Terra.

Entender o que é o espaço geográfico contribui para a busca por caminhos que melhor possam auxiliar na interpretação dos fenômenos socioespaciais. Na medida em que se identificam as características do espaço, entendendo-se as relaçóes que existem entre suas partes, torna-se mais simples estabelecer os caminhos de análise, pois, ao saber que o espaço é dinâmico e responde diferenciadamente aos processos, por exemplo, entende-se que a metodologia escolhida não pode tratá-lo de forma estática.

O objetivo deste texto é mostrar como o uso de ferramentas dos Sistemas de Informação Geográfica (SIGs) pode contribuir para a interpretação de fenômenos que ocorrem no espaço geográfico. Para isso, buscaram-se exemplos de trabalhos que utilizam diferentes ferramentas para analisar distintos fenômenos socioespaciais. Os 
exemplos apresentados focam processos socioeconômicos, não se considerando aqui os processos físicos. Os trabalhos retratam temas como geoestatística, análise multivariada, análise do uso e da ocupação do solo, entre outros.

As contribuições dessas geotecnologias à análise espaçotemporal têm sido amplamente discutidas e, para efeitos deste artigo, considera-se que seu uso associado ao exame de outros tipos de dados fornece ao pesquisador um rico material de análise das transformações socioespaciais.

\section{O espaço geográfico e suas transformações}

Como se disse, a compreensão do que configura o espaço geográfico e de como ocorrem suas transformações é necessária para se definir que caminhos podem ser seguidos em termos metodológicos para a análise dos processos socioespaciais. Considerando-se que não existe uma fórmula para analisar os fenômenos que se realizam no espaço geográfico, uma vez que estes são dinâmicos e não podem ser tomados em sua totalidade, é preciso entender o espaço e avaliar se os elementos escolhidos são suficientes para alcançar um resultado satisfatório na pesquisa. No intuito de identificar a contribuição das geotecnologias nesses estudos, apresentam-se a seguir as definiçóes sobre o conceito de espaço na visão de Milton Santos (1997a, 1997b, 2007, 2008), Doreen Massey (2000, 2004, 2009) e Roberto Lobato Corrêa (2003, 2006, 2009a, 2009b).

Santos (1997b) define o espaço como sistemas de objetos e de ações tomados em conjunto. Pense no que seria, conforme indica o autor, o conjunto indissociável e contraditório dos sistemas de objetos e de ações. Eis um exemplo.

Em algum ponto deste mundo, existe um espaço (no sentido físico da palavra, com árvores e cultivos, ruas e casas, rios e praças) em que vive um grupo de pessoas, talvez muito distante fisicamente de outros grupos de pessoas que vivem em outras porções de um espaço maior, no qual o delas esteja inserido. Nesse espaço físico, as pessoas plantam, constroem, reúnem-se para uma conversa, andam pelas ruas para ir a escolas, mercearias, farmácias. Pessoas nascem, pessoas morrem, e no mesmo momento em que tudo isso acontece, outras pessoas chegam, ao passo que algumas saem, havendo ainda aquelas que estão ali só de passagem.

A luz elétrica se torna uma realidade e, com ela, a televisão e um admirável mundo novo de possibilidades. Os mercados chegam para suprir a demanda crescente por alimentos, os hospitais se tornam necessários. Aqueles que saíram, para estudar ou trabalhar, voltam diferentes, com novas ideias e comportamentos. Os que somente passam também deixam suas ideias e seus costumes. As estradas de terra são agora vias por que automóveis circulam frequentemente. As indústrias se instalam, o comércio cresce e os empregos au- 
mentam, atraindo mais pessoas. Chegam os shoppings centers, o cinema e o teatro. A praça, cheia de pessoas em tempos remotos, é agora a casa de alguém sem emprego e moradia.

$\mathrm{O}$ celular já se tornou item de primeira necessidade. As amizades são feitas também pela internet, assim como as compras do mês e o pagamento das contas. Está tudo mais rápido, as pessoas correm para lá e para cá. Aquelas que podem, quando cansadas de tanto tumulto, falatório e correria, voltam para aqueles espaços isolados, pacatos e ávidos por mudanças.

Esses dois espaços, diferentes em população, áreas, costumes, crenças, clima, vegetação, número de escolas e de casas, são igualmente um conjunto de objetos naturais e criados pelo homem, mais a sociedade em movimento. Esses objetos não são independentes da sociedade, surgem ou deixam de existir, são valorizados ou não, de acordo com os interesses daquela; assim como a sociedade depende dos objetos para a realização de seu movimento. Santos (1997a) mostra que existe uma dialética entre os objetos e as relações características de cada momento histórico. Assim, o espaço constitui-se de relações e de objetos que servem de base para que essas relações aconteçam. "O espaço é resultado da ação dos homens sobre o próprio espaço, intermediados pelos objetos, naturais e artificiais” (Santos, 1997b, p. 71).

Os objetos vão sendo transformados e/ou substituídos segundo a lógica de produção de diferentes momentos históricos. "Em cada período histórico, temos um conjunto próprio de técnicas e de objetos correspondentes" (p. 67). O esquema 1 exemplifica essa mudança indicada por Santos, onde "A" são os elementos existentes no momento 1. Conforme a história se realiza, o espaço se transforma, estando presentes no momento 2 os novos elementos que surgem e aqueles de "A" que permanecem.

Esquema 1 - As transformaçôes espaciais em distintos momentos históricos, de acordo com Santos (1997b)

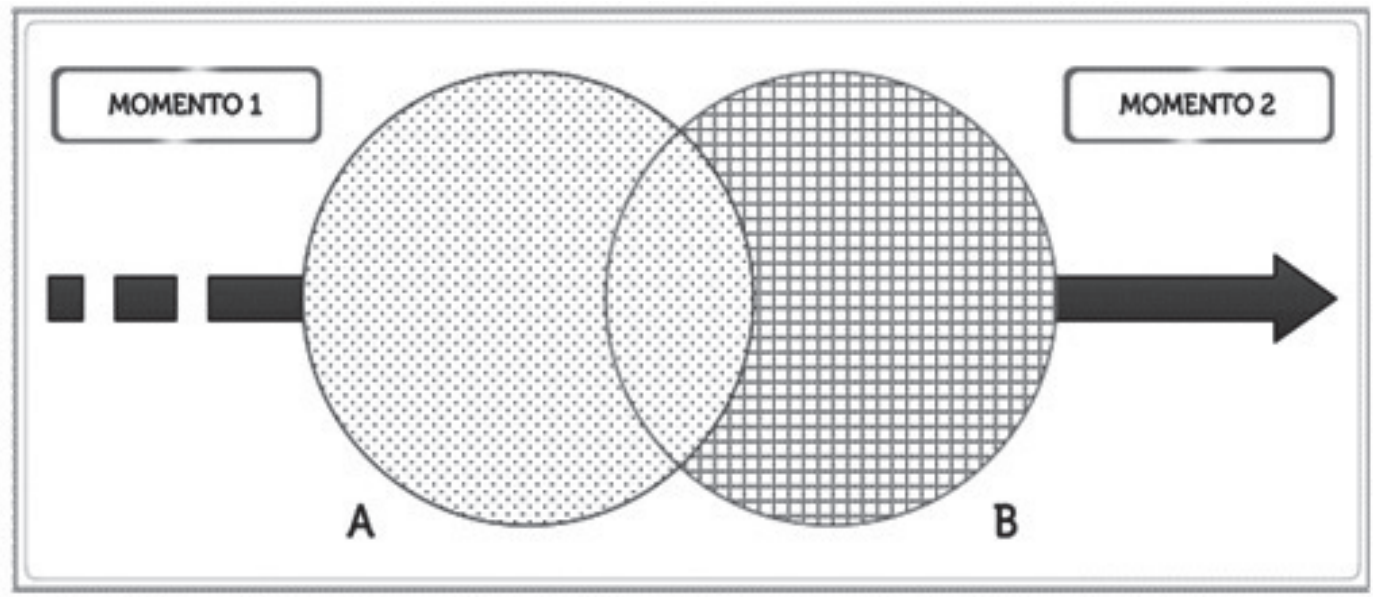

Organização: Renata da Silva Corrêa (2012). 
Apesar dessa permanência no espaço ao menos na aparência, as formas de A possuem um novo significado, um novo conteúdo histórico e só podem ser compreendidas segundo as variáveis existentes no momento 2 .

Segundo Santos, é "pelo movimento geral da sociedade que apreendemos o movimento geral do espaço” (2007, p. 38). E é por meio do trabalho que o homem realiza seu movimento sobre o espaço, aplicando energia sobre a natureza (natural ou já modificada) para sua reprodução. Ao longo da história, o homem cria, recria e inova em suas ações, de acordo com as técnicas de que dispõe e com as possibilidades econômicas, políticas e culturais. Nesse movimento, a natureza se transforma, tornando-se cada vez mais artificial, socializada e tecnificada. Novos objetos são criados, enquanto antigos são eliminados ou ganham novas funçôes; formam-se conjuntos de objetos que influenciam as ações do homem e que são por estas modificados (Santos, 1997a).

Esse conjunto de objetos compõe-se de heranças da história natural da superfície terrestre mais o resultado da ação humana objetivada; constitui aquilo que Santos (1997a) considera também a configuração territorial, ou seja, a materialidade do espaço físico, formada por elementos naturais ou criados pela ação humana.

As ações humanas se referem à realização de um propósito, são resultados de necessidades naturais ou criadas e se distinguem segundo a escala de comando e a de sua realização (Santos, 1997a). Nem sempre são iguais; não são raras as transformações espaciais que ocorrem por determinação ou influência de fatores externos ao local.

Aqui se tem um ponto interessante, no qual os pensamentos de Massey (2000, 2004) são válidos, pois indicam que esses fatores externos não são parte de uma lógica que opõe aquilo que está dentro e o que está fora do local, como se este fosse constituído por identidades/entidades exclusivamente internas. A autora alerta para a questão de se pensar o lugar em um sentido local, particular, dada a atual fase em que se encontra a globalização. Para ela, o lugar não deve ser pensado, portanto, com o intuito de resgatar identidades construídas internamente para justificar atitudes reacionárias; ao contrário, deve ser pensado em um sentido progressista, que identifica influências do externo na constituição das identidades e dos lugares.

Segundo Massey, a visão reacionária do lugar traz consigo o fato de sua identidade ser algo singular, essencial, e construída voltada para dentro. A autora põe-se a favor de uma integração positiva entre o global e o local, na qual o lugar é algo não estático, uma vez que agrupa interações espaciais, sendo elas próprias processos. $\mathrm{O}$ lugar não pode ser definido por fronteiras rígidas, que contrapõem o interno e o externo, mas o que pode ser evidenciado são as ligações com esse externo, que também faz parte do que caracteriza o lugar (com seus conflitos e suas múltiplas identidades).

Massey (2004) afirma que existe uma inter-relação entre a construção das identidades/entidades e a do espaço/espacialidade, que faz parte de um processo contínuo 
de coconstituição. $\mathrm{O}$ espaço é, assim, produto de inter-relações; sendo que estas não se encontram já delineadas seguindo uma linha sequencial do tempo em que todos os espaços evoluem. Esse tempo global (considerando-se aqui a escala em que ele ocorre) está acontecendo, mas simultaneamente aos tempos locais, dos cotidianos, das conversas na porta de casa, no mesmo instante em que um avião carrega gente de "todo canto para qualquer canto do mundo".

Além de o espaço ser produto de inter-relações, sempre abertas e inacabadas, é ainda possível que haja nele a multiplicidade. Segundo Massey $(2004,2009)$, a interação existente no espaço só se realiza porque neste há a multiplicidade, o que significa que nos espaços coexistem múltiplas histórias, infinitas inter-relações singulares. As possibilidades do "acontecer diferente", da não linearidade dos espaços no tempo e de que a multiplicidade abra caminho para inúmeros arranjos diferenciados permitem concluir que os espaços são diferentes, ainda que se considere todo o movimento "globalizante" do qual fazem parte.

De acordo com Santos (2007), processos semelhantes possuem respostas variadas em diferentes espaços, considerando-se a dinamicidade e a diversidade dos elementos que os compõem. Então, o espaço é um híbrido, é sistema de objetos e de ações tomados em conjunto, que se transformam conforme modificaçôes nos meios instrumentais e sociais de que os homens dispóem a cada período histórico. Esses meios, ou sistemas técnicos, envolvem maneiras de produzir e de se relacionar, revelam o encontro de condiçôes históricas (econômicas, políticas, sociais, culturais), em que mudanças nos sistemas técnicos são também mudanças nos objetos e nas formas de ação e, consequentemente, no espaço (1997a).

A atualidade caracteriza-se, nesse sentido, por um sistema técnico marcado pela rapidez de difusão, indiferença ao meio instalado, racionalidade e artificialidade. Há uma unicidade e uma universalidade das técnicas que se realizam por seu caráter sistêmico e pela capacidade de inserção dos sistemas técnicos locais numa história técnica e social mais abrangente. Logo, os objetos e as ações são cada vez mais carregados da mesma racionalidade; tornam-se universais e funcionam no nível do global. Nesse sentido, os lugares vivenciam processos constantes de revalorização mediante exigências globais, em um processo infindável de confronto, e por vezes de conflito, entre o novo e o velho, o interno e o que vem de fora (Santos, 1997a, 1997b, 2008).

Para compreender as mudanças de diversas naturezas pelas quais passam variados espaços, Santos propõe uma análise de acordo com quatro categorias que devem ser apreendidas simultaneamente, estrutura, processo, função e forma, pois os movimentos da totalidade social, ao modificarem as relações entre os componentes da sociedade, alteram os processos, incitam novas funções. Do mesmo modo, as formas geográficas 
se alteram ou mudam de valor; e o espaço se modifica para atender às transformações da sociedade (Santos, 2007, p. 55).

No quadro 1, organizado a partir de Santos (2008) e de Corrêa (2009a, 2009b), expóe-se o significado de cada categoria mencionada anteriormente.

Quadro 1 - Categorias de análise do espaço

\begin{tabular}{|c|c|c|}
\hline Forma & $\begin{array}{l}\text { Santos (2008) } \\
\text { Aspecto visível ou padrão de objetos. }\end{array}$ & $\begin{array}{l}\text { Corrêa }(2009 a, 2009 b) \\
\text { Formas criadas na superfície terrestre. É o recipiente da } \\
\text { função. }\end{array}$ \\
\hline Função & Uma tarefa ou atividade esperada. & $\begin{array}{l}\text { Atividades que garantem a existência e reprodução da } \\
\text { sociedade. São mutáveis, criadas e recriadas; ressignifi- } \\
\text { cadas. }\end{array}$ \\
\hline Estrutura & Inter-relação das partes de um todo. & Própria sociedade com suas dimensōes. \\
\hline Processo & Ação contínua que implica um resultado. & $\begin{array}{l}\text { Mecanismos e ações que permitem o movimento da es- } \\
\text { trutura/sociedade. } \\
\text { Movimento de transformação da sociedade/Estrutura } \\
\text { em movimento. }\end{array}$ \\
\hline
\end{tabular}

Fonte: Santos (2008), Corrêa (2009a, 2009b).

Organização: Renata da Silva Corrêa (2012).

Essas categorias constituem, para Santos (2008), uma unidade dialética, a totalidade. Nesse sentido, as formas sozinhas não explicam o espaço; é preciso analisar os processos que levam à construção ou ao desaparecimento delas, pois as ações que determinam o surgimento ou o reaproveitamento de formas antigas se encontram em níveis e escalas diversas, podendo estar no local ou em outras partes do mundo.

Não apenas os processos atuam no surgimento das formas, mas estas também podem influenciar o movimento da sociedade. Nesse "processo de realização geográfica da sociedade" (Santos, 2008, p. 60), as noções de tempo e de escala são fundamentais: primeiro porque as formas não são apenas do presente, mas também do passado; segundo porque existe uma produção seletiva do espaço.

Analisando as categorias apontadas por Santos (2008), Corrêa (2009a, 2009b) sugere a consideração do significado, com o objetivo de ampliar e enriquecer as categorias propostas por Santos como necessárias ao método geográfico. Ao resgatar essas categorias, Corrêa apresenta relações existentes entre processo e forma, por considerar que esse par dialético mantém a "integralidade da conexão" indicada por Santos.

A primeira relação identificada é a de convergência, quando dois processos distintos podem convergir para a mesma forma. O segundo caso é o da divergência, o que significa que um mesmo processo pode impactar diferentemente cada lugar, produzin- 
do manifestações distintas do mesmo processo. Isso porque condições internas, como as ações de políticos, a infraestrutura e a lei existentes e a aceitação das pessoas, variam em cada lugar. Nesse sentido, consegue-se compreender a maneira pela qual os espaços vão se diferenciando, ainda que os processos neles presentes sejam os mesmos.

A refuncionalização ocorre quando formas do passado assumem novas funções no tempo presente. Os processos que levaram à construção dessas formas existiam no tempo 1, mas os que explicam a nova função assumida encontram-se no tempo 2 .

A todo momento, na sociedade, as pessoas (agentes ou atores) estão desenvolvendo atividades que podem originar alguma materialidade, uma forma física, concreta. Os processos responsáveis por esse movimento são os chamados processos espaciais, que atuam como mediadores entre os processos sociais e as formas espaciais.

As transformações dos processos em formas espaciais ocorrem considerando-se dois fatores importantes: a escala e a intercausalidade existente entre processo e forma. Segundo Corrêa (2009a, 2009b), processos gerais são escalarmente transformados em formas locais, pois sofrem interferências de condições regionais, nacionais e locais. Em acordo com os pensamentos de Santos (2008), o autor mostra que as relaçóes processo/ forma deixam marcas na paisagem, que são também a matriz de novos processos.

Retomando Santos (2007), entende-se que ocorre uma mediação entre a estrutura social e seu conteúdo (que variam a cada fase histórica) e as formas. Essa mediação pode ser entendida quando se consideram as funções e os processos que possibilitam o movimento de transformação da sociedade.

Até o momento, sabe-se que o espaço é dinâmico, composto por objetos e ações que se relacionam em um movimento contínuo de inserção de novos elementos (fixos ou fluxos) e de revalorização dos já existentes. Por ser uma instância da sociedade - assim como a economia, a cultura e a ideologia -, por estar contido nela, o espaço está, a todo momento, reconfigurando-se (Santos, 2008). Espaço e paisagem se transformam continuamente, acompanhando o movimento de transformação da sociedade. Mas essa transformação ocorre em ritmos e intensidades diferenciados em cada porção do espaço.

Embora os espaços apresentem processos que perpassam uma lógica global, o que os tornaria iguais ao menos na aparência, possuem histórias distintas, condiçóes e elementos particulares, e, ainda que os mesmos processos se realizem - por exemplo, a instalação de uma indústria -, os resultados nunca serão iguais. Em cada lugar vai existir uma combinação particular daquilo que Santos (2008) considera os elementos do espaço: os homens, as firmas, as instituiçôes, o meio ecológico e as infraestruturas (fluxograma 1). 
Fluxograma 1 - Os elementos do espaço a partir de Santos (2008)

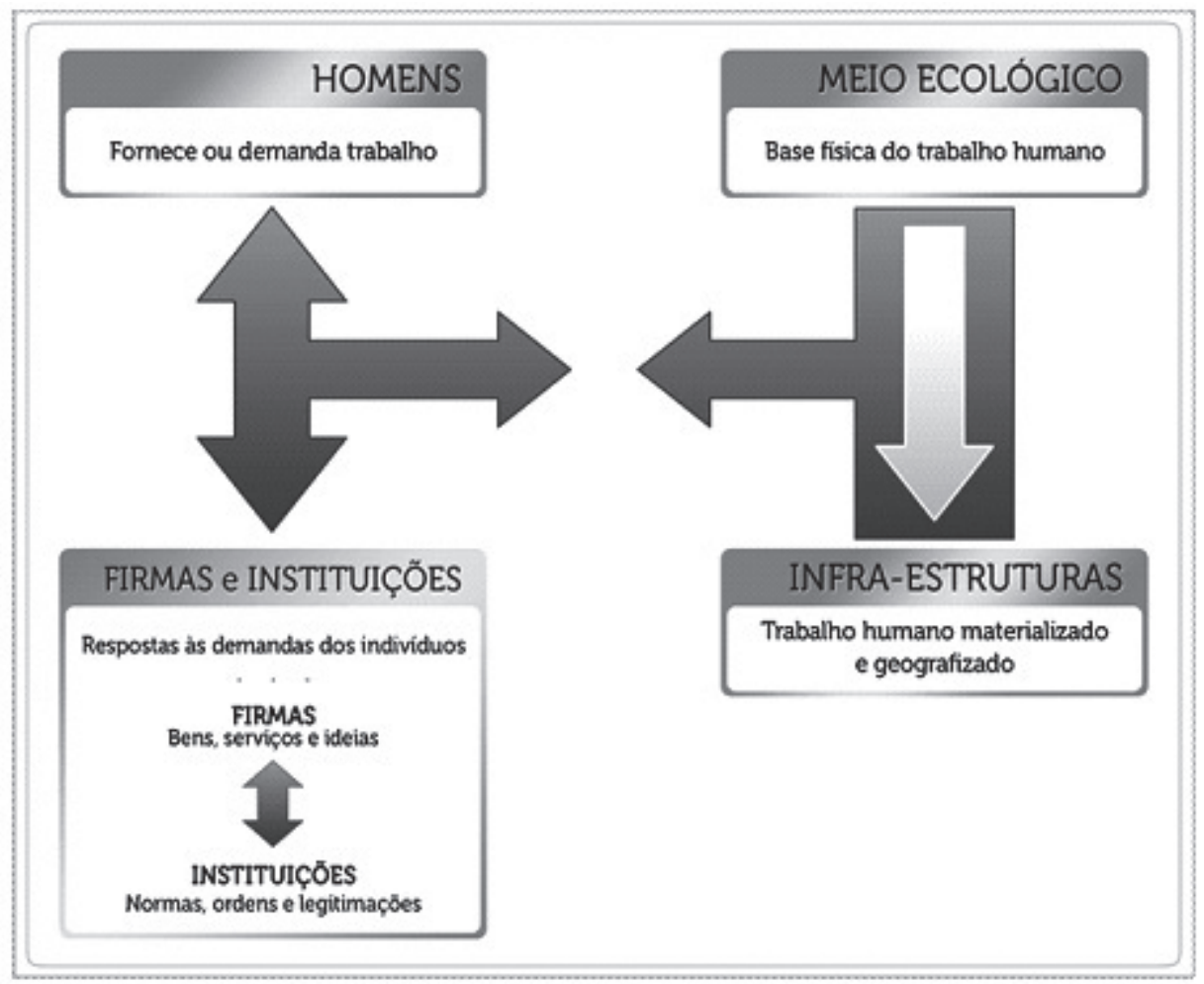

Organização: Renata da Silva Corrêa (2011).

De acordo com Santos (2008), existem uma intercambialidade e uma redutibilidade entre os elementos do espaço que se complexificam com o desenvolvimento histórico. As funções entre os homens e as firmas e instituições e as funções entre estas se confundem e se entrelaçam, assim como o meio ecológico se torna cada vez mais humanizado e tecnificado. "A cada momento histórico, cada elemento muda seu papel e sua posição no sistema temporal e no sistema espacial e, a cada momento, o valor de cada qual deve ser tomado de sua relação com os demais elementos e com o todo" (Santos, 2008, p. 20).

Os elementos que constituem o espaço variam quantitativa e qualitativamente, sendo, portanto, considerados variáveis. Em cada lugar, esses elementos possuem um valor particular. "O valor da variável não é função dela própria, mas de seu papel no interior de um conjunto” (p. 22). Cada grupo de elementos do espaço não é homogêneo, como também não são homogêneas as possibilidades de interação entre eles em cada lugar, que variam conforme a combinação da técnica e dos componentes do capital de seus elementos. 
A partir do que se expôs, identifica-se que o espaço geográfico é constituído por objetos (naturais ou criados) e por açóes emanadas de atores variados, responsáveis pela criação de novos objetos ou pela determinação de novas funções aos já existentes. Os objetos, por sua vez, também podem influenciar as ações, condicionando-as, e, dessa maneira, os espaços se transformam numa combinação de fatores culturais, políticos, econômicos e técnicos que variam em diferentes momentos históricos (Santos, 1997a). O espaço é, também, produto de inter-relações, em que é possível a existência da multiplicidade e do acontecer simultâneo de histórias diversas, cada qual com relativa autonomia. Por ser relacional e inacabado, o espaço é a esfera, ainda, do imprevisível, de inter-relações não planejadas. Considerado sob esses aspectos, o espaço contém a "produtividade da incoerência"; nele existem potencialidades, sendo, dessa forma, "fonte de produção de novas trajetórias, de novas estórias" (Massey, 2004, p. 18).

Como se vê, o espaço é movimento, é transformação que se realiza em sua forma e conteúdo. Nesse sentido, para analisar as transformaçôes que ocorrem nos espaços, é necessário considerar não apenas as alterações físicas, materiais, mas também as ações que levam a estas, os elementos responsáveis pelas transformações. A reflexão sobre os caminhos de operacionalização do trabalho e de interpretação do objeto de estudo é parte da construção metodológica da pesquisa, lembrando que os métodos definidos nesta devem ser compatíveis com as qualidades intrínsecas dos objetos.

\section{A metodologia na geografia e o uso das geotecnologias na análise espaçotemporal}

$\mathrm{Na}$ geografia, as bases teórico-metodológicas que nortearam os estudos baseiam-se no positivismo clássico, no positivismo lógico, no materialismo histórico e dialético e na fenomenologia. Nessas bases, o desenvolvimento da geografia divide-se em correntes de pensamento: a clássica ou tradicional se baseia no positivismo lógico, com destaque para as leituras naturalistas e o determinismo ambiental; a neopositivista, cuja base é o positivismo lógico, está ligada à racionalidade, à linguagem matemática e à criação e aplicação de modelos em busca de padróes para interpretar os fenômenos que ocorrem no espaço geográfico; a mais crítica pauta-se na perspectiva dialética entre a teoria e o objeto, com temas vinculados às questôes sociais e ao reconhecimento do caráter social do espaço; e a fenomenológica valoriza a perspectiva subjetiva, focando o estudo da relação homem/espaço a partir de valores, crenças, símbolos e comportamentos.

Como descrito em Suertegaray (2005), o fazer geográfico do período clássico da geografia consistia em localizar, observar, descrever e explicar. Os estudos sobre o espaço geográfico eram compartimentados em temas como população, economia, aspectos naturais, em que as características naturais e sociais eram descritas com base na empiria, na observação das paisagens e dos fenômenos. Passado esse período, os estudos geográ- 
ficos passaram a ser desenvolvidos sob a ótica do método neopositivista, valorizando a linguagem matemática e a lógica formal e privilegiando o estudo "das cidades, suas funçōes e sua classificação hierárquica" (p. 22), na busca por explicações gerais sobre o espaço. Procedimentos estatísticos para o tratamento das informações são amplamente utilizados, o que garante a confiabilidade dos resultados.

Como crítica a essa geografia de base neopositivista, os estudos da corrente crítica buscam entender o espaço geográfico a partir de seu processo de formação histórica, desenvolvendo discussões sobre os conflitos sociais e os problemas ambientais. Há um reconhecimento do caráter social do espaço e uma revalorização da questão política. No âmbito da influência da fenomenologia nos estudos geográficos, a busca é pela compreensão do espaço, que é vivido e interpretado por meio dos significados, valorizando-se a diferença e a perspectiva subjetiva por meio de análises qualitativas das relações que os sujeitos estabelecem com os espaços.

Atualmente, o que se vê é uma diversificação dos trabalhos, que se associam a diferentes bases filosóficas e conjugam distintos materiais e técnicas de análise. De acordo com Alves (2008), a complexidade dos fenômenos que ocorrem no espaço geográfico dificulta a escolha de um método único de investigação por causa da velocidade e da dinamicidade de suas transformaçôes. O aporte teórico-metodológico, que técnicas e materiais serão utilizados, deve ser definido pelo pesquisador à medida que seu objeto de estudo for construído. Não há restrições quanto à maneira pela qual a pesquisa deve ser desenvolvida; o que deve existir é uma coerência quanto aos métodos de interpretação e de pesquisa definidos para isso. Segundo Alves,

as técnicas, que são meios para se chegar a um fim, devem estar de acordo com a fundamentação teórico-metodológica, e, por isso, a seleção de um método não contempla essa diversidade técnica e teórica tão vasta. Cabe ao geógrafo fazer sua escolha em relação ao método e à técnica, pois a complexidade do espaço geográfico é profunda e ele deve ter cuidado para não cair em um reducionismo ou senso comum (2008, p. 239).

Nesse sentido, o desafio que se coloca para aqueles que estudam as transformações do espaço geográfico, principalmente para a geografia, é a integração das ferramentas de análise espacial oferecidas pelo conjunto das geotecnologias com todo o aporte teórico, conceitual e metodológico que as ciências acumularam ao longo dos séculos. No âmbito desta pesquisa, essas ferramentas se apresentam como mais uma possibilidade de representação da dinamicidade do espaço geográfico ao permitir a agregação de diversos planos de informação - como mapas de solo, redes de transporte, cadastros fundiários, vegetação, concentração populacional -, que, analisados em associação com 
outros dados de socioeconomia, podem indicar tendências, explicar fenômenos, refutar ideias previamente estabelecidas, entre outros.

A existência de um estreito vínculo entre a geografia e as geotecnologias tem possibilitado discussões sobre o futuro da geografia ou até sobre o surgimento de uma ciência da geoinformação, como designam Câmara, Monteiro e Medeiros (2001). Os autores propõem uma busca nas bases científicas da geografia a fim de estabelecer os fundamentos epistemológicos da pretensa ciência da geoinformação. Para tanto, fazem um resgate pelas distintas escolas de pensamento geográficas indicando as relações existentes entre as noçōes desenvolvidas e o geoprocessamento, como a noção de "unidade de área", com a caracterização de unidades homogêneas e os atributos que as singularizam.

Ainda segundo esses autores, a noção de espaço geográfico na perspectiva da geografia crítica não possibilita uma associação imediata entre conceitos da ciência da informação espacial, mas traz as limitações presentes nos sistemas de informação atuais, que representam essencialmente as formas, não sendo ainda capazes de ilustrar computacionalmente os processos e as funções que dão movimento à estrutura social. Conforme os autores, as "representaçôes computacionais geométricas" e os "modelos funcionais" têm como resultado as materializações do espaço, e não a complexidade da transformação socioespacial.

Nesse ponto, faz-se uma crítica no sentido de que somente as técnicas do geoprocessamento e seus produtos gerados não são autossuficientes, ou seja, sem informações e dados complementares e um conhecimento construído em bases consistentes, as análises podem ser tendenciosas e imbuídas de interpretações errôneas da realidade. Acredita-se que a geografia pode, sim, fornecer os fundamentos para análises mais sólidas, agregando ao seu aporte científico o novo campo de possibilidades metodológicas fornecido pelas geotecnologias. Para Fitz (2008), duas opçôes de encaminhamento epistemológico se apresentam: a constituição de uma "geografia tecnológica", como novo campo do saber geográfico; ou uma "ciência da geoinformação", como novo ramo do conhecimento. $\mathrm{O}$ autor continua, afirmando que "essa caracterização, a nosso ver, não implicaria uma nova ciência, mas, sim, uma nova abordagem epistemológica da ciência, a qual denominamos 'geografia tecnológica'. Uma concepção que une características da geografia, da informática e da cartografia” (pp. 28-9).

Concorda-se com o autor, quando este diz que a contemporaneidade se apresenta à geografia como um momento de reflexão sobre suas orientações científicas. Entretanto, não se pode deixar que a geografia se restrinja a práticas mecânicas que são constantemente questionadas sobre sua essência geográfica. Sabe-se que, em outro momento de sua história, a aproximação da geografia com o pragmatismo e as técnicas estatísticas e matemáticas foi duramente criticada pela corrente do pensamento que a sucedeu. A chamada geografia crítica muito questionou a prática dos geógrafos lógico- 
-positivistas, caracterizando-a como a-histórica e generalista, entre outros. Sobre isso, Corrêa mostra que, ao liberar a geografia quantitativa de alguns pressupostos, como a a-historicidade dos fenômenos sociais, alguns elementos se apresentam como importantes meios de compreensão da organização do espaço. Nesse sentido, afirma que

as representações matricial e topológica devem, em nosso entender, constituir-se em meios operacionais que nos permitam extrair um conhecimento sobre localizaçóes e fluxos, hierarquias e especializaçôes funcionais, sendo, neste sentido, uma importante contribuição que, liberada de alguns de seus pressupostos como a planície isotrópica, a racionalidade econômica, a competição perfeita e a-historicidade dos fenômenos sociais, pode ajudar na compreensão da organização espacial (2003, p. 23).

Assim como as ferramentas que estavam disponíveis à dita geografia quantitativa, as técnicas do geoprocessamento apresentam hoje meios cada vez mais rápidos e com grande nível de detalhamento para as análises das ações dos homens sobre o ambiente.

\section{Utilização de ferramentas SIG na interpretação de fenômenos socioespaciais - alguns exemplos}

A representação da superfície da Terra pode ser tarefa muito simples, como também pode envolver modelos matemáticos, algoritmos e mapeamentos sistemáticos de determinadas áreas dessa superfície. Caso se peça a duas pessoas, um médico e um engenheiro cartógrafo, por exemplo, para representar no papel alguma porção do espaço físico, uma praça, talvez, é muito provável que exista uma diferença nos desenhos de ambos os profissionais. No desenho do médico, as árvores, as construções, as ruas em volta e os demais elementos que compóem a praça talvez tenham limites e proporções com pouca correspondência com o real. A preocupação do cartógrafo, por outro lado, será com a exatidão das posiçôes dos objetos, a proporção entre o tamanho destes no real e no papel, as distâncias entre eles, a forma e outros elementos cuja utilização tem o objetivo de elaborar uma representação mais próxima do real.

Assim, sempre buscando a máxima correspondência com aquilo que existe e se encontra distribuído na superfície terrestre, seja natural ou construído, a cartografia avançou e tem à disposição, hoje, uma gama de ferramentas computacionais que não apenas facilitaram o trabalho dos profissionais, como também possibilitaram a difusão das informações espaciais para diversas áreas do conhecimento.

Essa "onda", poderia dizer-se, de uso da informação espacial, desde o caráter mais estratégico e voltado ao planejamento à simples localização de um endereço, foi possível por causa de alguns fatores que possibilitaram o desenvolvimento dos atuais 
SIGs, como a evolução dos computadores pessoais, dos sistemas gerenciadores de banco de dados relacionais e a incorporação de inúmeras funções de análise espacial, a partir da década de 1980 (Câmara, Davis e Monteiro, 2001). Esses sistemas integram o conjunto de ferramentas matemáticas e computacionais que se desenvolvem no grupo das geotecnologias, apontadas por Fitz como

as novas tecnologias ligadas às geociências e correlatas, as quais trazem avanços significativos no desenvolvimento de pesquisas, em ações de planejamento, em processos de gestão, manejo e em tantos outros aspectos relacionados à estrutura do espaço geográfico (2008, p. 11).

A partir delas, foi possível o processamento informatizado (ou geoprocessamento) de dados georreferenciados, o que acelerou e facilitou a elaboração de mapas e modelos de representação da superfície terrestre, além de possibilitar que o usuário (gestor, planejador, técnico e outros) elaborasse análises mais consistentes, uma vez que os SIGs permitem a combinação de mapas diversos e dados de diferentes características.

Nesta parte do texto, apresentam-se alguns exemplos de estudos na área da geografia que incorporam o uso das ferramentas SIG em seu processo de análise do espaço. Dessa forma, o artigo de Napoleão e Castro (2006) busca compreender, por meio da análise espacial, quais eram as relações entre as condições de vida da população e a taxa de criminalidade urbana na Região Administrativa de Campinas, em São Paulo, no ano 2000.

Os autores criaram o Índice de Condiçōes de Vida (ICV), a partir de dados demográficos, de educação, renda e infraestrutura (IBGE, 1991, 2000; Informações dos municípios paulistas, Fundação SEADE, 1991; e Atlas do desenvolvimento humano no Brasil, PNUD, 1998), e o Índice de Criminalidade Urbana (ICU), com dados sobre crimes contra a pessoa e o patrimônio (Departamento de Administração e Planejamento da Secretaria de Segurança Pública de São Paulo, 2000, Núcleo de Análise de Dado).

Para a obtenção dos índices, relativizaram-se os dados coletados, dividindo-se seus valores pelo parâmetro regional estabelecido, que foi o maior valor da informação na série de dados. Após a relativização dos dados, atribuíram-se pesos, de maneira que se diferenciasse a influência das variáveis, e, posteriormente, agruparam-se os dados em cinco classes de acordo com a fórmula de Sturges. Os índices criados variam de 0 a 1, de forma que o fenômeno se torna mais intenso conforme a proximidade com o valor 1 .

No software Idrisi, elaboraram-se os mapas com os índices que sintetizam os blocos demografia, educação, rendimento, infraestrutura urbana e criminalidade urbana. Posteriormente, analisou-se o comportamento da relação espacial entre o ICV e ICU, relacionando-os por meio da álgebra de mapas, em que foram multiplicados os mapas 
representativos do ICV e do ICU, respeitando-se as seguintes relações: quanto menor o ICV, maior o ICU; quanto maior o ICV, maior o ICU; quanto menor o ICV, menor o ICU; e quanto maior o ICV, menor o ICU.

As funçôes de análise espacial dos SIGs permitem que estudos como o de Napoleão e Castro (2006) sejam elaborados avaliando o comportamento espacial de variáveis socioeconômicas e das relações que existem entre elas. A espacialização desses resultados torna os SIGs ferramentas importantes a serem utilizadas no planejamento e na gestão do território, além de sua capacidade de integrar e cruzar grande número de dados de forma rápida e eficiente. No estudo supracitado, os autores têm o cuidado de não serem deterministas mediante os resultados encontrados, atentando para a necessidade de estudos em outras escalas de análise para compreender as variações entre a criminalidade e a qualidade de vida. Concordando-se com eles, lembra-se aqui que o espaço geográfico não é homogêneo e os elementos explicativos dos fenômenos socioespaciais perpassam as mais variadas escalas. Nesse sentido, torna-se imprescindível analisar os processos específicos que justificam a configuração dessas relações espaciais.

$\mathrm{Na}$ esfera institucional, a publicação $O$ estado do ambiente - indicadores ambientais do Rio de Janeiro, 2010, do Instituto Estadual do Ambiente do Rio de Janeiro, em seu capítulo sobre os indicadores de pressão, trabalha com dados e informações agregados de forma a elaborar o Índice de Vulnerabilidade Socioeconômica (ISVE) dos municípios. A construção do ISVE considerou as dimensões social e econômica e a infraestrutura de saneamento dos municípios do Rio de Janeiro. Para a avaliação dessas dimensões, trabalharam-se os indicadores de renda, educação, demografia, saúde, mercado de trabalho e saneamento ambiental. Coletaram-se os dados no Censo demográfico do Instituto Brasileiro de Geografia e Estatística (IBGE, 2000), na Fundação Centro Estadual de Estatísticas, Pesquisas e Formação de Servidores Públicos do Rio de Janeiro (CEPERJ) e no Instituto Estadual do Ambiente (INEA).

O indicador de demografia é composto por variáveis que caracterizam o perfil demográfico e a mobilidade populacional (taxa de crescimento vegetativo, índice de envelhecimento, índice de dependência, taxa de pobreza, taxa de indigência, taxa líquida de migração e taxa de migração pendular). $\mathrm{O}$ indicador de educação agrega dados sobre faixas de escolaridade e taxa de alfabetização da população (taxa de alfabetização da população maior que 15 anos e porcentagem de chefes de domicílio sem ou com menos de um ano de instrução, de um-três anos, de quatro-sete, de oito-dez). $\mathrm{O}$ indicador de mercado de trabalho é obtido pela avaliação da formalidade e informalidade do mercado de trabalho. O indicador de renda considera as faixas de rendimento dos chefes de domicílio (\%) e a renda per capita (em reais). O indicador de saúde é uma síntese de dados sobre longevidade e mortalidade: expectativa de vida da população (em anos); taxa de mortalidade infantil (menores de 1 ano, entre 1-5 anos); taxa de mortalidade 
infantil por doença diarreica aguda (DDA); e taxa de internação por dia. O indicador de saneamento ambiental é uma síntese dos indicadores "destino da coleta de esgoto", "destino da coleta de lixo" e "forma de abastecimento de água".

Embora na publicação não se explicite a metodologia adotada para a criação dos indicadores e do índice, estes variam de 0 a 1, sendo maior a vulnerabilidade quanto mais próximo de 1 . Representou-se cada indicador em mapas que sintetizam o resultado de análises estatísticas realizadas sobre os dados coletados, em que o mapa representativo do ISVE é o resultado da associação entre os demais indicadores criados. Como se disse, a análise espacial desses indicadores pode orientar a elaboração e a execução de políticas públicas, de forma que o direcionamento dos investimentos em saúde, educação, saneamento ou outros fatores responsáveis pela alta vulnerabilidade dos municípios seja realizado de maneira mais eficiente.

Outro exemplo de trabalho que utiliza os SIGs em sua produção é a dissertação elaborada por Corrêa (2012), na qual a autora analisou as transformações socioespaciais ocorridas nos municípios de Angra dos Reis e Paraty a partir das décadas de 19601970. Para se analisar as transformações, utilizaram-se imagens de satélite (Landsat 2 e 5) dos anos 1977, 1990 e 2010, a fim de gerar mapas por meio dos quais se pôde verificar a expansão das áreas urbanas. Para a elaboração dos mapas, selecionaram-se imagens de satélite Landsat 2 MSS de 1977, com resolução espacial de 80 metros, e Landsat 5 TM de 1990 e 2010, cuja resolução é de 30 metros, adquiridos no site do Instituto Nacional de Pesquisas Espaciais (INPE).

Após a seleção e os procedimentos de correção e de tratamento nas imagens, procedeu-se à reamostragem dos pixels, à composição de bandas, ao georreferenciamento e ao mosaico das imagens. A escala de trabalho estabelecida foi 1:100.000. Após a definição das classes temáticas, que foram "pasto", "vegetação", "área urbana" e "área urbana consolidada”, realizou-se a classificação supervisionada da imagem de 2010 pelo método da máxima verossimilhança e, a partir desta, identificaram-se as diferenças do uso para o ano de 1990. Para a produção do mapa de áreas urbanas de 1977, efetuou-se a classificação visual da imagem.

Efetivou-se uma análise para os períodos de 1977 a 1990 e de 1990 a 2010. Para o primeiro período, realizou-se uma análise qualitativa entre os resultados dos mapas e, para o posterior, uma comparação quantitativa. Isso porque as diferenças entre as resoluçõos espectrais e espaciais das imagens não permitem uma compatibilidade entre os resultados dos mapas a fim de que se possa realizar uma comparação quantitativa entre 1977 e 1990.

Em conjunto, trabalhou-se com dados econômicos e populacionais de censos produzidos pelo IBGE, dados da Empresa de Assistência Técnica e Extensão Rural (EMATER) e outros utilizados na elaboração de quadros e tabelas sobre a estrutura 
socioeconômica dos municípios. Selecionaram-se fotografias antigas fornecidas pelo Instituto do Patrimônio Histórico e Artístico Nacional (IPHAN), IBGE e outras fontes para ilustrar as transformaçōes apresentadas.

O exame desses dados se realizou em confronto a outros, qualitativos, adquiridos pelas experiências de campo, da vivência da autora nos municípios estudados e da leitura de material bibliográfico sobre o tema. Ao agregar dados e informaçóes que não apenas aqueles fornecidos pelo mapeamento elaborado, a autora conseguiu apresentar de maneira mais ampla as mudanças verificadas e, além disso, a busca por referências sobre o tema permitiu que o entendimento das transformações fosse alcançado de forma mais consistente. É nesse sentido que os mapeamentos de uso e cobertura devem ser desenvolvidos, associados sempre a outros tipos fontes de dados e informaçóes, de maneira que se possam contextualizar e compreender os processos que levam às mudanças.

Há algum tempo, os SIGs têm sido utilizados em análises sobre o espaço geográfico no que tange a temas correlacionados à área da saúde. Nesse sentido, o trabalho de Leite et al. (2011) é um bom exemplo de como a utilização dessas ferramentas pode contribuir para a compreensão do comportamento espacial de certas doenças, como a dengue. Nessa pesquisa, os autores buscaram analisar a distribuição espaçotemporal da dengue nos municípios de Minas Gerais de 2006 a 2009 e sua relação com o perfil socioeconômico e a temperatura média anual das localidades.

Criaram-se quatro mapas de incidência da doença, elaborados a partir do cálculo definido pelo Departamento de Informática do Sistema Único de Saúde (DATASUS), em que a incidência de dengue (Id) se dá pela relação entre o número de casos de dengue em residentes $(\mathrm{N})$ e a população total residente $(\mathrm{P})$ multiplicado por 100 mil. Por meio dos dados do Sistema de Informação de Agravos de Notificação (SINAN) e do IBGE, a incidência foi calculada, e os municípios foram classificados, de acordo com o padrão adotado pelo Programa Nacional de Controle da Dengue, como de baixa, média e alta incidência.

Quanto ao desenvolvimento socioeconômico dos municípios, os autores mapearam o Índice Firjan de Desenvolvimento Municipal (IFDM) para o ano de 2006, que se baseia nas condiçóes de emprego e renda, educação e saúde, varia de 0 a 1 e pode ser baixo, regular, moderado ou alto. Além desses, foi criado um mapa da temperatura média anual com dados coletados no Instituto Nacional de Meteorologia (INMET/ MG) de 1992 a 2008.

Por meio do estudo, foi possível identificar áreas susceptíveis ao aumento dos casos de dengue e estabelecer algumas relaçôes entre as áreas de incidência da doença, as condições de vida da população e a temperatura média anual dos locais em tela. Para essa análise, os autores consideraram o nível de urbanização dos municípios, a densida- 
de populacional e a dificuldade de notificação dos casos de dengue em algumas regiões do estado decorrente da ineficiência no diagnóstico da doença.

Esse estudo é um exemplo de como a utilização de diferentes camadas possibilita a análise de relações que se manifestam no espaço geográfico. Cabe ao pesquisador avaliar os resultados dessas associações com seu conhecimento sobre a realidade e com estudos complementares que ratifiquem ou não as relações observadas em ambiente SIG.

No sentido também de analisar a relação entre distintos planos de informação, o artigo de Arend et al. (2011) objetiva, baseado em rotinas multicritério de apoio à decisão, auxiliar na identificação de locais propícios à implantação de Sistemas Orgânicos de Produção Agropecuária (SOPA) no município de Arroio do Meio/RS. Para isso, definiram-se os critérios de aptidão e de restrição considerando-se estas condições ambientais e econômicas: a declividade; o uso da terra; a distância de fragmentos florestais, de estradas e do centro consumidor; a presença de área de preservação permanente; os recursos hídricos; e a área urbanizada.

A partir de uma imagem de satélite de 2009, com resolução de $5 \mathrm{~m}$, elaborou-se um mapa de uso e cobertura da terra, com o apoio de coordenadas geográficas demarcadas para as classes de uso definidas. A base cartográfica foi criada em escala 1:50.000 a partir das cartas topográficas da Diretoria do Serviço Geográfico do Exército.

Para tornar os cinco fatores comparáveis entre si, seus valores foram padronizados de acordo com a Lógica Fuzzy, em que se buscou identificar o grau de aptidão à implantação dos sistemas orgânicos. Após a padronização, comparou-se cada fator com os demais, indicando-se uma relação de importância entre eles por meio de uma matriz de comparação pareada. Dessa forma, foi possível determinar o peso de cada fator e multiplicá-lo pelos cinco mapas padronizados e pelo mapa das restriçôes absolutas. Como resultado dessa agregação, gerou-se um mapa de aptidão com valores numéricos que foi reclassificado em classes temáticas de aptidão: baixa, média baixa, média, média alta, alta e a classe que contém as áreas com restrições absolutas.

Essa pesquisa é um exemplo de como os SIGs podem ser utilizados como ferramentas de apoio à gestão ao integrar dados de naturezas diversas e inter-relacioná-los usando métodos que buscam tornar as análises mais próximas das relações que ocorrem no real.

\section{Consideraçóes finais}

A possibilidade de trabalhar espacialmente um conjunto de dados econômicos, sociais e ambientais tem feito dos SIGs ferramentas aliadas no estudo de fenômenos que se processam no espaço geográfico. A integração de formas georreferenciadas proporcionando as análises espaciais de grupos de dados dispostos em tabelas é o que difere 
essas análises daquelas puramente estatísticas. Embora as análises realizadas com auxílio de SIGs sejam rápidas e aceitáveis quando se tem a consciência da precisão dos dados utilizados, é preciso avaliar a coerência dos resultados encontrados, identificar os porquês e determinar as possíveis causas do comportamento da distribuição espacial dos elementos analisados.

Acredita-se que as ferramentas disponíveis nos SIGs ainda não sejam amplamente utilizadas em estudos da chamada geografia humana. Comumente, sua aplicação tem se direcionado mais aos estudos dos fenômenos físico-naturais do que às dinâmicas das dimensões social, econômica e cultural. A apreensão desses movimentos em forma de mapas é algo difícil e perigoso, uma vez que as dinâmicas socioespaciais são menos previsíveis e mais subjetivas, se comparadas, por exemplo, com as características pedológicas e geomorfológicas. Identificar padrões espaciais e representá-los cartograficamente sem correr o risco de tornar estanques as dinâmicas que se realizam no espaço geográfico configura-se como um grande desafio àqueles que buscam integrar as ferramentas SIG em suas pesquisas.

Contudo, embora a dificuldade exista, a utilização dos SIGs para analisar os fenômenos socioespaciais se mostra eficiente quando integrada a outros tipos de dados e informações que auxiliem a interpretação dos resultados alcançados.

\section{Referências}

ALVES, Flamarion Dutra. "Consideraçôes sobre métodos e técnicas em geografia humana". Dialogus, Ribeirão Preto, 2008, v. 4, n. 1, pp. 227-41.

AREND, Mara Regina et al. "Múltiplos critérios de apoio à decisão em SIG para a promoção de Sistemas Orgânicos de Produção Agropecuária no município de Arroio do Meio/RS". Anais do Simpósio Brasileiro de Sensoriamento Remoto (SBSR). Curitiba: INPE, 2011, pp. 423-30. Disponível em http:// www.dsr.inpe.br/sbsr2007/biblioteca/. Acesso em set. 2011.

CÂMARA, Gilberto; DAVIS, Clodoveu; MONTEIRO, Antônio Miguel V. (orgs.). Introdução à ciência da geoinformação. São José dos Campos: DPI/INPE, 2001. Disponível em http://www.dpi.inpe.br/ gilberto/livro/introd/index.html. Acesso em mai. 2011.

CÂMARA, Gilberto; MONTEIRO, Antônio Miguel V.; MEDEIROS, José Simeão de. Representaçôes computacionais do espaço: um diálogo entre a geografia e a ciência da geoinformação. São José dos Campos: DPI/INPE, 2001. Disponível em http://www.dpi.inpe.br/geopro/trabalhos/epistemologia. pdf. Acesso em abr. 2011.

CORRÊA, Renata da S. Transformações socioespaciais em Angra dos Reis e Parati (RJ) de 1960-1970 a 2010 (dissertação). UERJ, 2012, 133 p.

CORRÊA, Roberto L. "Espaço, um conceito-chave na geografia". In CASTRO, Iná Elias; GOMES, Paulo Cesar da C.; CORRÊA, Roberto L. (orgs.). Geografia: conceitos e temas. 6 ed. Rio de Janeiro: Bertrand Brasil, 2003, pp. 15-47.

__. "Interaçôes espaciais". In CASTRO, Iná Elias de; GOMES, Paulo Cesar da C.; CORRÊA, Roberto L. (orgs.). Exploraçôes geográficas. 2 ed. Rio de Janeiro: Bertrand Brasil, 2006, pp. 279-318. 
- Aula magna ministrada pelo Programa de Pós-Graduação em Geografia da Universidade do Estado do Rio de Janeiro. Rio de Janeiro, 16 set. 2009a.

—. Processo, forma e significado. Uma breve consideração. Rio Grande do Sul, 2009b. Disponível em http://www.ihgrgs.org.br/Contribuicoes/Processo_Forma_Significado.htm. Acesso em set. 2011.

FITZ, Paulo Roberto. Geoprocessamento sem complicação. São Paulo: Oficina de Textos, 2008.

FUNDAÇÃO SISTEMA ESTADUAL DE ANÁLISE DE DADOS (SEADE). Anuário estatístico do estado de São Paulo. São Paulo, 1999. Disponível em http://www.seade.gov.br. Acesso em abr. 2002.

INSTITUTO BRASILEIRO DE GEOGRAFIA E ESTATÍSTICA (IBGE). Censo demográfico de 1991. Rio de Janeiro, 1993.

. Censo demográfico de 2000. Rio de Janeiro, 2002.

LEITE, Marcela Ribeiro et al. "Distribuição espaçotemporal da dengue nos municípios de Minas Gerais e sua relação entre o desenvolvimento municipal e a temperatura". Anais do Simpósio Brasileiro de Sensoriamento Remoto (SBSR). Curitiba: INPE, 2011, pp. 8397-404. Disponível em http://www.dsr. inpe.br/sbsr2007/biblioteca/. Acesso em set. 2011.

MASSEY, Doreen. “Um sentido global de lugar”. In ARANTES, Antônio A. (org.). O espaço da diferença. Campinas: Papirus, 2000, pp. 176-85.

—. "Filosofia política da espacialidade: algumas considerações". GEOgraphia, Niterói, jul.-dez. 2004, v. 6 , n. 12 , pp. 7-23.

—. Pelo espaço. Uma nova visão política da espacialidade. Traduzido por Rogério Haesbaert e Hilda Maciel. Rio de Janeiro: Bertrand Brasil, 2009.

NAPOLEÃO, Patrícia Rosa Martines e CASTRO, José Flávio Morais. “Análise espacial da criminalidade urbana e das condições de vida na Região Administrativa de Campinas (SP) no ano 2000". In GERARDI, Lucia Helena de Oliveira e CARVALHO, Pompeu Figueiredo de. (orgs.). Geografia: açôes e reflexões. Rio Claro: UNESP/IGCE/AGETEO, 2006, pp. 181-202.

PROGRAMA DAS NAÇÕES UNIDAS PARA O DESENVOLVIMENTO NO BRASIL (PNUD). Desenvolvimento humano e condiçôes de vida: indicadores brasileiros. Brasília, 1998.

SANTOS, Milton. Metamorfoses do espaço habitado. 5 ed. São Paulo: Hucitec, 1997a.

—. A natureza do espaço. Técnica e tempo. Razão e emoção. 2 ed. São Paulo: Hucitec, 1997b.

- Pensando o espaço do homem. 5 ed. São Paulo: EDUSP, 2007.

- Espaço e método. 5 ed. São Paulo: EDUSP, 2008.

SUERTEGARAY, Dirce M. Antunes. "Notas sobre epistemologia da geografia". Cadernos Geográficos, Florianópolis, mai. 2005, n. 12, pp. 1-63. 